\title{
AMENDMENTS
}

\section{Author Correction: Sea-level driven land conversion and the formation of ghost forests}

Matthew L. Kirwan (D) and Keryn B. Gedan

Correction to: Nature Climate Change https://doi.org/10.1038/s41558-019-0488-7, published online 27 May 2019.

In the version of this Review originally published, the results of ref. ${ }^{77}$ were incorrectly reported: in the sentence beginning "Analysis of topography and land use..., ' $39,000 \mathrm{~km}^{2}$ ' should have read ' $19,572 \mathrm{~km}^{2}$ ', and ' $6,000 \mathrm{~km}^{2}$ ' should have read '4,056 $\mathrm{km}^{2}$; in the sentence beginning "First, current and projected barriers..., ' 15\%' should have read ' $20 \%$ '; and, in the sentence beginning "Finally, the area of land..., ' $39,000 \mathrm{~km}^{2}$ ' should have read ' $19,572 \mathrm{~km}^{2}$, 'nearly three times' should have read 'larger than', and 'larger than' should have read 'similar to'. All these errors have now been corrected in the online versions. These changes do not affect the findings of the Review.

Published online: 2 August 2019

https://doi.org/10.1038/s41558-019-0568-8

\section{Publisher Correction: Reduced probability of ice-free summers for $1.5^{\circ} \mathrm{C}$ compared to $2{ }^{\circ} \mathrm{C}$ warming}

Alexandra Jahn (iD)

Correction to: Nature Climate Change https://doi.org/10.1038/s41558-018-0127-8, published online 2 April 2018.

In the version of this Article originally published, the labels showing the degree of warming in panels c and h of Fig. 2 were incorrectly stated as ' $20^{\circ} \mathrm{C}$ '; the correct labels are ' $2.0^{\circ} \mathrm{C}$. These have now been amended in the online version. 